\title{
ESTÉTICAS DA SUBJETIVAÇÃO: A INTERFACE ENTRE PSICANÁLISE E LITERATURA
}

\author{
Vinícius Romagnolli Rodrigues Gomes ${ }^{1}$ orcid.org/0000-0002-1119-6817
}

\begin{abstract}
RESUMO O laço que une psicanálise e literatura é estreito. Freud desejava ser reconhecido como homem da ciência, mas isso não o impediu de ser reconhecido como um grande escritor, tendo o mesmo recebido o prêmio Goethe. Neste artigo, tentamos demonstrar que é possível compreender a criação do pensamento freudiano e do novo homem por ele concebido, por meio de suas ressonâncias e confluências com a literatura fantástica, que por sua vez, faz uma sobreposição de temas aparentemente inconciliáveis, a saber: o real e a fantasia. Há, em Freud, uma dicotomia entre o cientista e o poeta, o iluminista e o criativo especulativo. A própria noção que Freud cunhou do humano, é a de um ser contraditório e em constante conflito. A singularidade da obra de Freud resulta em grande parte desse convívio e tensão entre os dois polos.
\end{abstract}

Palavras-chave: Psicanálise; Literatura; Estética.

\section{AESTHETICS OF SUBJECTIVITY: THE INTERFACE BETWEEN PSYCHOANALYSIS AND LITERATURE}

\begin{abstract}
The bond that unites psychoanalysis and literature is narrow. Freud wished to be recognized as a man of science, but that did not stop him from being recognized as a great writer, having earned the Goethe award. In this article, we try to demonstrate that it is possible to understand the creation of Freudian thinking and the new man conceived by him, through its resonances and confluences with fantastic literature, which in turn, overlaps seemingly irreconcilable themes: reality and fantasy. There is, in Freud, a dichotomy between the scientist and the poet, the enlightenment and the speculative creative. The very notion that Freud coined from the human is that of a contradictory being in constant conflict. The uniqueness of Freud's work results largely from this coexistence and tension between the two poles.
\end{abstract}

Keywords: Psychoanalysis; Literature; Aesthetic.

${ }^{1}$ Doutorando UNESP-Assis; viniciusrrgomes@gmail.com. 
[v.1, n.2] Jul./Dez. 2020

\title{
Apresentação: a origem estética da psicanálise
}

\author{
"Os poetas e escritores são aqueles que \\ dão seu testemunho ao mundo de que é \\ preciso encontrar palavras para fazer face \\ ao i-mundo" \\ (Marco Antônio Coutinho Jorge)
}

Foi a passagem da Poética para a Estética que possibilitou a Freud erguer sua psicanálise. Essa é a tese de Jacques Rancière (2005) em sua obra $O$ inconsciente estético. Se a Poética desde Aristóteles falava sobre os recursos estilísticos e técnicos para fazer poesia, a Estética, por sua vez, buscava a relação do belo com o verdadeiro sob a égide do discurso filosófico.

Freud encontra uma racionalidade na análise da arte que pode ser transferida para uma análise dos sintomas histéricos, dos sonhos e do próprio inconsciente. Ele cita os artistas sobretudo para mostrar à comunidade de médicos e cientistas, que a obra daqueles dá testemunho à racionalidade e à fantasia que estes não queriam ver. Nesse sentido, as obras e modos de pensar a arte do século XIX, constituíram uma equivalência entre racionalidade da arte e do inconsciente. Schelling e Hegel abordaram a Estética analisando produções artísticas como frutos da união entre processo consciente e inconsciente (Rancière, 2005).

As formas de racionalidade erigidas pela filosofia da arte possibilitaram a construção da racionalidade inconsciente. A Estética abriu caminho para se pensar, a partir do modo filosófico, o que não se pensava por esse viés. Freud, tendo seguido essa abertura, se utilizou da arte para construir a racionalidade do sintoma e postular o inconsciente (Rancière, 2005).

Assim, o psicanalista importa uma racionalidade que começa a ser aplicada à poesia com a fundação da Estética e superação da Poética para compreender fenômenos psíquicos. Aquilo que era proveniente da ordem da sensação, do corpo e da expressão artística, ou mesmo a sintomatologia enigmática, possuía um sentido inconsciente passível de entendimento e de teorização racional. Dessa forma, a Estética como ramo 
[v.1, n.2] Jul./Dez. 2020

filosófico, a qual busca explicar a arte, abriu possibilidade de uma compreensão formal do saber dos poetas (Rancière, 2005).

Peyon (2011) diz que apesar da Estética abrir caminho para a teorização do inconsciente, a poesia é uma invenção diante do desconhecido da vida, por meio da qual se cria a própria vida. O que passa a acontecer através da Estética, é uma inclusão da poesia no campo daquilo que pode ser pensado teoricamente, e isso abre espaço para Freud formular o inconsciente como lugar dos impulsos recalcados e desconhecidos do humano, e, de mesmo modo, tentar explicar teoricamente seu funcionamento.

Rancière (2005) considera que a noção de inconsciente freudiano surgiu a partir do inconsciente estético, em meio a um regime de pensamento no qual havia abertura para se pensar contradições e oposições coexistidas em contraposição ao regime "poéticorepresentativo" ou "clássico", os quais funcionavam a partir de uma hierarquia rígida e previamente estabelecida, que visava excluir toda e qualquer ambiguidade ou paradoxo no campo da Arte.

Dessa forma, a psicanálise surge a partir de um espírito que contempla os contrários; no Zeitgeist da Modernidade, no qual o pathos convive com o logos; num cenário marcado pelo pensamento de Schopenhauer, Nietzsche, Zola, Flaubert, Baudelaire, Dostoiévski, entre outros. Um ethos marcado pela entropia niilista e que ilumina de modo sombrio o pathos dentro do $\log o s$, o não-sentido e os limites da linguagem. Em suma, a psicanálise teria nascido em meio a um contexto onde já não havia hierarquia fixa entre o que deve ou não ser escutado, tendo em vista que nada é irrelevante numa narrativa e que toda palavra importa (Rancière, 2005).

\section{Do fantástico ao enigmático}

Há um campo híbrido entre o fantástico e misterioso mundo da literatura, e o enigmático mundo psicanalítico. No fim do século XIX, temos um cenário onde o enigma convive e, ao mesmo tempo, compete no mistério do fantástico e da histeria. O homem psicanalítico convive com o homem fantástico. O artista é um duplo do psicanalista, duplo amado e temido (Kon, 2003).

Kon (2003) faz uma psicanálise poética e mostra como a psicanálise assume sua força de literatura. Viajar não é dado a todos, apenas àqueles que se dispõem à alteridade. 
[v.1, n.2] Jul./Dez. 2020

A palavra literária lançada ao mundo como coisa inútil, encontra junto ao desconhecido, num tempo imprevisto, sua força transformadora. Somos seres inconformados com nossa condição conflitante e aspiramos pelo re-encontro com nossa origem sempre re-criada.

O programa iluminista buscava ampliar o domínio do conhecimento e suprimir a tentação do milagre ou a sedução do mistério, transformando-os em um enigma decifrável. A loucura e o sobrenatural deveriam ser capturados pelo discurso, tornando-se "doença mental" e ganhando inteligibilidade e controle. Da literatura fantástica para a psicanálise, assistimos à transição do homem-fantástico para o homem psicanalítico. O inconsciente freudiano irá acolher o antigo maravilhoso, tentando desfazer e re-fazer o mistério essencial do fantástico. A respeito do sobrenatural, Guy de Maupassant (1883) afirma que o termo saiu das vidas dos homens do fim do século XIX e denunciou a rejeição do misterioso, que se tornou o inexplorado. É nesse ponto que surge a psicanálise (Kon, 2003).

É possível compreender a criação do pensamento freudiano e do novo homem por ele concebido, por meio de suas ressonâncias e confluências com a literatura fantástica, a qual faz uma sobreposição de temas aparentemente inconciliáveis, a saber: o real e a fantasia. Diante do fantástico, surge a questão: trata-se de um milagre ou de um enigma? A psicanálise tenta iluminar o fantástico, não deixando espaços para o milagre e mistério, tomando-os como enigmas inconscientes (Kon, 2003).

A psicanálise possui uma potência ficcional e é necessário realçar esse poder e não o camuflar, cuidando para não revesti-la de uma máscara cientificista e tomá-la como verdade dada do ser. A força ficcional precisa ser acolhida no ofício do psicanalista, para que assim o encontro analítico assuma sua potência de criação de realidade e sua força de ficção verdadeira, característica do seu modo de ser; ou seja, um modo de fantasiar cientificamente (Kon, 2003).

Freud tem uma atitude ambivalente quanto aos artistas. Há uma oposição entre desvelamento e criação. Seria o psicanalista um arqueólogo? Aquele que desvenda e revela um conhecimento preexistente, esquecido e soterrado pela repressão? Ou seria um artista que opta pela via da criação com o emprego de sua fantasia de realidades sempre inéditas?

Para Kon (2003), a psicanálise necessita apresentar-se por via de um caráter literário criador de realidades, ficcional, assumindo uma força que é sua; ao passo que 
[v.1, n.2] Jul./Dez. 2020

resiste ao selo severo de ciência, o qual conforma e é uma maneira poderosa, mas não exclusiva de compreender o mundo. Psicanalisar é criar, abrir espaço para geração de histórias, fazer e refazer trajetos, de modo a reinaugurar, a cada momento, significações inéditas para o enredo que passamos a construir para nós mesmos.

\section{A relação de Freud com a literatura}

O laço que une psicanálise e literatura é estreito. Freud desejava ser reconhecido como homem da ciência, mas isso não o impediu de ser reconhecido como um grande escritor. Recebeu o prêmio Goethe na qualidade de "incomparável explorador das paixões humanas". Sua obra é habitada pela companhia de vários escritores, bem como Goethe, Shakespeare, Schiller, Heine, Hoffman; além de interlocutores contemporâneos, como Schnitzler, Zweig, Rolland, Mann.

Freud, homem da ciência, reconhece na Dichtung - atividade poética e do imaginário - um acesso privilegiado à verdade psíquica. O pensamento freudiano subsiste graças não só às suas descobertas, mas também por habitar poeticamente a língua; ou seja, pelo encontro do pensamento com a poesia. Tanto a literatura como a psicanálise, visam por meio de seus procedimentos próprios, explicar a complexidade da alma humana com seus conflitos obscuros. Freud lança mão de termos alemães que não possuem equivalência em outras línguas europeias; a saber, Ditcher para o criador literário e de ficções (narrador, dramaturgo, escritor) e Dichtung para criação literária ou atividade poética/do imaginário (Pontalis \& Mango, 2013).

Goethe, em sua autobiografia Poesia e verdade (1811), dirá que a verdade mais elevada só pode ser acessada pelo escritor literário ou poético. Pontalis e Mango (2013) lembram de Paul Valéry, o qual considerava a produção poética proveniente da poietica, do grego poien - que implica fazer, criar, fabricar com as palavras. Nesse sentido, a ação que faz, tem mais paixão que a coisa feita (Pontalis \& Mango, 2013).

Freud tinha admiração e inveja da capacidade de fantasiar e criar do poeta; ele não cessa de questionar a respeito da produção poética e dos efeitos que ela produz no receptor/leitor. Os poetas se tornam aliados de Freud em sua investigação racional. Freud reconhece na atividade poética/literária da Dichtung, um processo de elaboração psíquica capaz de transformar as sensações, os sentimentos e os afetos humanos em figuras de 
[v.1, n.2] Jul./Dez. 2020

linguagem, num dizer poético que preserva o frescor das experiências originárias e primitivas (Pontalis \& Mango, 2013).

Em sua obra O poeta e o fantasiar (1908/2015), Freud visa enquanto pesquisador do íntimo da vida psíquica, compreender a produção das fantasias. O neurótico oferece suas fantasias da vida cotidiana ao psicanalista, seus sonhos, brincadeiras e devaneios que interessam a ele. Freud tinha curiosidade em saber de onde o escritor retira seu material e como logra nos tocar profundamente com seus escritos, provocando em nós profundas emoções. Ele ironiza o escritor que não costuma dar resposta a respeito disso, e assim, diminui a distância que o separa de pessoas comuns, dizendo coisas como "em cada homem existe um poeta", algo que Rilke, seu amigo, sugere em suas Cartas a um jovem poeta (1929).

Freud (1908/2015) considera o escritor um "sonhador em pleno dia"; e a obra literária e o devaneio, como a substituição daquilo que um dia foi a brincadeira infantil. Sugere que busquemos na infância os primeiros traços da atividade criativa, vez que para a criança, a brincadeira é sua ocupação, e ao brincar, se comporta como criador literário, construindo para si um mundo próprio. A língua alemã mostra o parentesco entre brincadeira infantil (Spiele) e produções literárias (Lustpiel, Trauerspiel). A criança leva sua brincadeira a sério (enquanto o adulto se leva muito a sério).

No texto de 1908, Freud argumenta que o oposto da brincadeira não é a seriedade, mas sim a realidade; e a criança, por vezes, se apoia nessa realidade para brincar, como por exemplo ao brincar de ser gente grande. Nesse sentido, coisas reais que não nos trariam prazer, podem nos proporcionar o prazer no jogo da fantasia, como as emoções dolorosas que podem ser fonte de fruição de leitores.

Ao crescer, a criança se empenha para aprender a realidade com seriedade, e quando se torna adulto, pode recordar de suas brincadeiras e equiparar suas ocupações sérias àquelas brincadeiras, livrando-se do pesado fardo imposto pela vida e alcançando o ganho proporcionado pelo humor. Ao parar de brincar, renunciamos ao ganho de prazer que tínhamos com ela; sobre isso, Freud (1908/2015) diz que nada é tão difícil para nós quanto renunciar a um prazer que já experimentamos.

No fim das contas, não renunciamos, apenas trocamos uma coisa por outra substituta. $\mathrm{O}$ adulto não brinca, mas fantasia, constrói devaneios e sonhos diurnos. $\mathrm{O}$ adulto muitas vezes se envergonha de suas fantasias e as oculta. Deles, se espera a 
[v.1, n.2] Jul./Dez. 2020

seriedade e atuação no mundo real, ou seja, que não brinquem ou fantasiem. Fantasia é associada como algo infantil e ilícito. As crianças não têm motivos para esconder seus desejos, inclusive brincam de ser grandes, o que expressa o desejo de ser adulto um dia.

Um adulto que fala de suas fantasias e desejos inconscientes, não suscita simpatia em nós; pelo contrário, via de regra nos escandalizamos com isso. Quando um escritor ou poeta nos brinda com seus escritos, sentimos prazer. A ars poética está nessa técnica de superar o choque ligado às barreiras que separam cada Eu do Outro. Há um ganho de prazer estético na apresentação das fantasias por parte do escritor, um prazer preliminar ou brinde incentivador, sendo a fruição da obra literária fruto da libertação de tensões em nossa psique. Além disso, o escritor nos permite desfrutar de nossas próprias fantasias sem recriminação e pudor (Freud 1908/2015).

\section{A escrita em psicanálise e na literatura}

Birman (2019) indaga se haveria uma especificidade da escrita psicanalítica e uma diferença para outras modalidades de escrita. Seria a escrita psicanalítica similar à literatura nas suas características ficcionais e poéticas? Seria similar à filosofia com sua argumentação? Ou seria próxima da ciência natural com verificação de provas? Ainda há o campo das ciências humanas com a consistência teórica dos enunciados e a referência a um campo empírico.

Segundo Birman (2019), por não envolver enunciados matemáticos, a escrita psicanalítica não se pauta no modelo da ciência natural, e dessa forma se aproxima mais da ciência humana. Entretanto, pela presença de procedimentos ficcionais, se aproxima do discurso literário. Possui ainda um estilo argumentativo na metapsicologia que a aproxima da escrita filosófica.

Freud, em sua correspondência com Fliess, lamenta que suas narrativas clínicas eram lidas pelos colegas médicos como narrativas literárias e não científicas. Isso amargurava o pai da psicanálise em sua ambição de ser um homem da ciência. KrafftEbbing disse a Freud, que seus estudos sobre a etiologia da histeria não passavam de um conto de fadas científico (Birman, 2019).

A interpretação dos sonhos teve uma recepção da crítica que colocava em relevo a dimensão estética e não científica da obra. Deste modo, começaram os ruídos que 
[v.1, n.2] Jul./Dez. 2020

opunham a escrita clínica de Freud à escrita médica. O estilo de Freud assemelhava-se ao escrito literário do romance. Além disso, a teoria freudiana era vista como próxima da arte e literatura, e estranha aos cânones científicos e médicos da época. A respeito disso, Birman (2019) indaga: seria um mal-entendido ou um bem entendido?

Ademais, Birman (2019) argumenta que o campo da medicina reconhecia, desde então, que o discurso psicanalítico não se adequava aos moldes da medicina científica. Freud coloca em suas obras a ênfase nas diferenças entre psicanálise e medicina; um exemplo disso é reconhecer a importância da fantasia nas perturbações corporais, ou ainda no destaque que confere ao discurso e à linguagem na experiência psicanalítica por conta do psiquismo ser constituído como aparelho de linguagem.

A comunidade científica tinha razão em estranhar a escrita de Freud. As narrativas clínicas e médicas da época davam destaque para a enfermidade a partir de seus sintomas e sinais, enquanto a psicanálise, em contrapartida, buscava a compreensão do sujeito a partir do sintoma que assumia uma característica oposta. $\mathrm{Na}$ clínica médica, ele tinha valor negativo, ao passo que na psicanálise, possuía um valor positivo.

A narrativa psicanalítica põe em relevo o sujeito e seus impasses subjetivos, daí seu discurso se vale do modelo do romance e enfatiza o registro da ficção que estava ausente na narrativa médica. A experiência clínica de Freud era norteada pela interpretação da trama fantasmática do sujeito. A partir dessa articulação, ele concebe o aparelho psíquico fundado na realidade psíquica e não material (Birman, 2019).

A escrita em psicanálise tem como coordenadas os registros da linguagem: (interpretação), ficção (fantasia) e das intensidades (pulsão). Ela procura evidenciar a condição do sujeito na experiência analítica, bem como as formações do inconsciente, a saber: o sintoma, o sonho, o lapso, o ato falho e a piada. Todos os casos clínicos de Freud articulam o registro dos sintomas à história fantasmática dos analisandos. Nos dizeres de Birman (2019, p. 124), “a dívida da psicanálise em relação à literatura é evidente, pois esta forneceu um modelo de escrita pelo qual o discurso freudiano se norteou para empreender as suas narrativas clínicas".

Não por acaso, o método da associação-livre foi inspirado em uma obra literária de Borne, representante do Romantismo alemão. Freud confessa isso em uma carta de 1920, à Ferenczi. Na obra de Ludwig Borne (1786-1837), Freud leu recomendações de como se tornar um escritor que apontava para deixar as ideias fluírem livremente na 
[v.1, n.2] Jul./Dez. 2020

imaginação, sem censura e preocupação com a realidade externa. Assim como um escritor, o analisando pode criar ficções sobre sua existência e sua história, permeadas por suas fantasias. Birman (2019) lembra Jacques Derrida, o qual considera que em Freud, o aparelho psíquico é uma máquina de escrever, pela qual o inconsciente é concebido como uma cena de escrita, e a memória, por conseguinte, modelada por essa escrita. Tal escrita é atravessada pelo poder e pela ficção, por espectros e fantasmas, até a biografia é permeada pela ficção (Birman, 2019).

\section{Psicanálise entre ciência e literatura}

Freud afirmava que os artistas e poetas haviam precedido suas descobertas, e que a psicanálise seria uma formalização conceitual daquilo que estes haviam descoberto anteriormente. Freud colocou artistas no divã - como por exemplo em sua análise de Leonardo Da Vinci e Dostoiévski - para descobrir neles, sentidos ocultos a eles próprios, interpretando suas vidas a partir de suas obras. Freud adota um caminho distinto no caso da Gradiva, onde parte da obra com a finalidade de examinar hipóteses sobre o funcionamento da psicanálise. Se utiliza de obras para questionar a teoria e clínica psicanalítica, ou seja, pela arte é possível compreender melhor a psicanálise. O que está em jogo é a compreensão do sujeito a partir da psicanálise e da relação com a linguagem e a realidade; esta última está sempre aberta para a psicanálise e não possui respostas prontas (Silva Jr, 2019).

Ficção e arte são uma espécie de reduto do processo primário em meio a realidade cotidiana. Os artistas teriam perspicácia para o inconsciente, ao passo que o psicanalista estaria privado disso em vista do seu método científico. $\mathrm{O}$ artista ultrapassa o psicanalista pela liberdade que goza em seus meios. Freud aproxima a arte das formações sintomáticas que se satisfazem com a fantasia e se distanciam da realidade, o que faz com que recuse a aproximação da psicanálise com a ficção (Silva Jr, 2019).

A ficção, tal como trabalhada no texto $O$ Estranho (1919), possui o poder de colocar entre parênteses a realidade e os conteúdos imaginários numa espécie de suspensão da diferença entre realidade e ficção, chamada de ficcionalidade, que não é privilégio exclusivo da arte, mas também está presente de outro modo na psicanálise. Admitir que a psicanálise possui uma ficcionalidade poderia dificultar a ambição de Freud 
[v.1, n.2] Jul./Dez. 2020

em ter sua ciência reconhecida no rol das ciências naturais. Na ciência, nada é feito para que se coloque a realidade e ficção no mesmo plano e se suspenda uma distinção entre elas. A ficcionalidade ameaça Freud. Kraft-Ebing criticou a teoria da sedução de Freud ironicamente ao dizer que se tratava de um "conto de fadas científico". Freud confessa à Fliess um incomodo com seus relatos de caso que mais pareciam um romance (Silva Jr, 2019).

Freud parece se orgulhar do inquietante/estranho proveniente do retorno do infantil, mas mostra-se inseguro ao aproximar sua psicanálise dos poderes desrealizantes da ficção. No primeiro caso, o inquietante viria da ameaça da irrupção de forças obscuras evocadas na ficção com frequência, e isso não seria problema para Freud. No entanto, quando se trata da capacidade da ficção em forjar uma segunda realidade indistinta da realidade empírica, a aproximação com a psicanálise não é bem-vinda (Silva Jr, 2019).

As contradições na postura de Freud perante a literatura refletem, de algum modo, as complexas tensões no pensamento freudiano entre sua aspiração voltada para reconhecer sua ciência como natural, e a admiração pelos escritores, descritos em sua Autobiografia (1925) como tentação filosófica da juventude. Um detalhe importante: Freud abordou a metapsicologia da ficção quase exclusivamente a partir da primeira teoria das pulsões, sob a hegemonia do princípio do prazer, o que faz da ficção uma das formações de compromisso entre recalque e retorno do recalcado ao lado do sonho, do lapso e sintoma. (Silva Jr, 2019).

\section{Psicanálise e poesia}

Freud foi poeta a cada vez que o cientista ficava sem chão (Eduardo Peyon)

Peyon (2011) indaga sobre os motivos dos psicanalistas valorizarem tanto o poético. Freud mesmo o fazia, recomendando que indagássemos os poetas para irmos além. Lacan também dizia que o artista desbravava o caminho para o psicanalista. Nesse sentido, o que o poético nos ensina sobre a forma de conhecer da psicanálise?

Os avanços da ciência moderna no conhecimento da physis/natureza, implica uma redução, ou ao menos uma expectativa de redução do valor de verdade da poesia, a qual 
[v.1, n.2] Jul./Dez. 2020

seria excluída do campo de conhecimento oficial ou transformada em objeto racional da Estética, disciplina filosófica. Desde Platão, a poesia ficou excluída do campo oficial do conhecimento. Hegel foi o precursor da superação da verdade poética pela filosófica (Peyon, 2011).

A poesia surge como possibilidade de resposta humana frente ao mistério da vida. A ciência seria uma superação do modo poético do conhecimento acerca daquilo que se mostra desconhecido aos sentidos. O poético seria a manifestação mais originária na busca por uma compreensão da vida, é a emergência do ser, do desejo da ânsia visceral por compreender o enigma do mundo. Não houve e nem haverá superação do poético! Não há construção de conhecimento do poético, da sensibilidade, da intuição e da imaginação na relação com outro íntimo e estranho, próximo e distante (Peyon, 2011).

Freud, mesmo imbuído da construção de uma ciência nos moldes do cânone cientifico moderno, cita Goethe e Shakespeare incessantemente; considera que a interpretação do sonho se assemelha a uma frase poética. A poesia escapa do discurso lógico e objetivo, mas se mostra essencial quando queremos conhecer as causas mais íntimas e o limite da palavra. A ciência não suprime a questão da origem misteriosa que se coloca o tempo todo diante de nós. Existe algo que não se desvela no laboratório, nos exames do cérebro e não se mede através da racionalidade; essa coisa é impressa como hieróglifo em nós quando lemos a poesia que um outro contemporâneo ou pré-histórico nos enviou (Peyon, 2011).

O poético é, desde Homero, um remendo, jamais uma plenitude. O poético insiste em re-velar, velar novamente. O conhecimento não pode ser verdadeiro, assim se exclui a existência e seu mistério. Peyon (2011) salienta que Freud fez uma subversão ao apontar os limites do conhecimento construído pela consciência, indicando que o "eu não é senhor da sua própria casa". Freud convoca o poético em sua elaboração teórica, e rompe com o discurso filosófico e científico. Vico disse que a sabedoria poética pertence aos sentidos e a sabedoria filosófica da razão. Assim sendo, aonde os sentidos chegam primeiro, depois viria a racionalidade? Não seria essa concepção refém de um dualismo caduco entre mente racional e corpo sensual? (Peyon, 2011).

O poético se faz necessário sempre que a ignorância se apresenta ao humano, seja referente ao corpo, ao sexual, à morte ou origem. Freud destaca, no entanto, que não existe um desvelamento completo do inconsciente, e que o poeta re-vela o desconhecido, renova 
[v.1, n.2] Jul./Dez. 2020

o enigma e relança a verdade. O poeta constrói uma sabedoria sobre o desconhecido sem ter necessariamente consciência disso. O psicanalista teoriza sobre ou a partir da verdade que o poeta re-vela, mas este não sabe dizer se aquilo que o psicanalista construiu é de fato explicativo de sua criação. O poeta não precisa ter um saber teórico sobre sua arte (Peyon, 2011).

Apesar do modelo oriundo da Estética ter viabilizado a investigação racional do inconsciente, tal como propõe Rancière (2005), Freud, para ultrapassar as contradições de sua caminhada, lançava mão dos poetas. Por mais cientificista que Freud tentasse ser, a psicanalise se inscreve mais no campo da criação literária, de modo que a matéria tratada na psicanálise talvez tenha obrigado Freud a ser poeta, pois a teoria do homem remete a esse movimento de criação ficcional, fazendo-se um pouco literatura (Peyon, 2011).

De certo modo, ser psicanalista é possibilitar que o analisando escreva sua poesia, re-lance sua narrativa, re-construa seu passado, e assim, teça um novo mito sobre seu existir. Freud investiga um objeto irredutível aos cânones da objetividade do modelo cientifico de sua época, o que exige de seu pensamento invenções a cada vez que precisa avançar com sua teoria. Após o projeto para uma psicologia científica e o desejo de propor um aparelho psíquico com base nos processos neurofisiológicos, Freud vai poetizando ao erguer sua teoria do funcionamento da mente (Peyon, 2011).

Há em Freud uma dicotomia entre o cientista e o poeta, o iluminista e o criativo especulativo. Freud reconhecia em Goethe um bom exemplo da relação entre racionalidade e poesia, entre ciência e arte. Poesia é estruturante da obra de Freud. Nos dizeres de Peyon (2011, p. 118):

Freud criou, a partir de sua sensibilidade aos poetas e aos seus pacientes, e, simultaneamente, em acordo e em conflito com seu ideal cientificista, uma das maiores teorias sobre a alma humana. Isso não poderia ter sido feito sem poesia e desejo.

\section{Considerações finais}

Com a psicanálise, aprendi que somos seres fictícios (Borges também falou isso em sua obra); o próprio Freud, em sua juventude, tinha enorme apreço pela mitologia grega de Sófocles, pela Ilíada e Odisseia de Homero, por Hamlet de Shakespeare, e pelo 
[v.1, n.2] Jul./Dez. 2020

Dom Quixote de Cervantes, com suas inter-relações entre fantasia e realidade, entre razão e des-razão.

Em seu Dicionário amoroso, Roudinesco (2019) aponta que a dimensão da fantasia representa, em psicanálise, uma realidade deformada, remetendo justamente a ficção, fantasma, espectro e alucinação; fantasia é a realidade psíquica e não o equivalente a mentira, mas antes uma forma simbólica e alegórica de representar algo para a pessoa.

A virada para o século XX assistiu, no entanto, ao incremento do ideal positivista e iluminista de ciência e ao desencantamento do mundo, como denunciou Max Weber. Tudo isso concorreu para o apagamento da dimensão trágica e conflitiva da existência, e fez com que o discurso do homem comportamental e da neurociência ganhassem cada vez mais força, ambos propagando "a morte da psicanálise e do sujeito do inconsciente" (Roudinesco, 2019).

Freud era um iluminista, um cientista que apostava suas fichas na racionalidade, mas também era amplamente influenciado pelo romantismo alemão (em especial de Goethe), e assim se deparou com a imensidão do inconsciente, os limites da razão e da linguagem. O inconsciente freudiano acolhe o antigo "maravilhoso" e "misterioso" próprios do universo fantástico, os quais são tão retratados na literatura e mitologia. Por isso, nos dizeres de Inês Loureiro (2013), Freud era um "iluminista sombrio", uma expressão contraditória, não?

A própria noção que Freud cunhou do humano é a de um ser contraditório e em constante conflito. Se serve de alento, Mário Quintana (1997) pode nos consolar ao dizer que "quem nunca se contradiz, deve estar mentindo". O próprio Freud disse em carta a Romaind Rolland, que trabalhou ao longo de sua vida para desfazer algumas de suas ilusões e alusões da humanidade.

Thomas Mann (2015) aproxima essa postura freudiana de um aforismo de Nietzsche que diz "faça a ilusão desaparecer!". Eis o intento malogrado da psicanálise, pois por mais que nos esforcemos, não podemos viver sem um pouco de ilusão, justamente por não suportarmos tanta realidade. Para finalizar, cito Pontalis e Mango (2013, p. 215): Freud escritor? Freud cientista? E se a singularidade de sua obra, se o que ela tem de inclassificável, resultasse em grande parte desse convívio, dessa tensão entre os dois polos? 
[v.1, n.2] Jul./Dez. 2020

\section{Referências}

Birman, J. (2019). Escrita, memória e ficção em psicanálise. In Birman, J. Cartografias do avesso. Rio de Janeiro: Civilização Brasileira.

Freud, S. (2015). O poeta e o fantasiar. In Freud, S. Obras completas de Sigmund Freud. São Paulo: Companhia das Letras. (Trabalho original publicado em 1908)

Silva Jr, N. (2019). Psicanálise entre ciência e literatura In Silva Jr, N. Fernando Pessoa e a psicanálise. São Paulo: Blucher.

Pontalis, J-B. \& Mango, E. (2013). Freud com os escritores. São Paulo: Três estrelas.

Peyon, E.R. (2011). Poesia, psicanálise e conhecimento. São Paulo: Escuta.

Rancière, J. (2005). Inconsciente estético. São Paulo: Editora 34.

Kon, N. M (2003). A viagem: da literatura à psicanálise. São Paulo: Companhia das Letras.

Loureiro, I. (2013). A psicanálise entre luzes e sombras In Jacó-Vilela, A. M. História da Psicologia: rumos e percursos. Rio de Janeiro: NAU.

Mann, T. (2015). Pensadores modernos. Rio de Janeiro: Zahar.

Roudinesco, E. (2019). Dicionário amoroso da psicanálise. Rio de Janeiro: Zahar.

Quintana, M. (1997). Quintana de bolso. São Paulo: L\&PM. 